\title{
Cultural Value and Connotation of Yugur Folk Songs Heritage*
}

\author{
Pengyuan Zhang \\ School of Music \\ Northwest Minzu University \\ Lanzhou, China
}

\begin{abstract}
Due to the "dispersion" of migration and the lack of writing, Yugur folk songs carry more cultural functions and connotations. This paper reveals its cultural value and connotation from different perspectives, such as the memories it carries on ethnic history and culture, the continuity of mother tongue life, the continuity of production and life experience, the "marginal preservation" of ancient national culture, the verification of the traditional culture exchange of the Silk Road, its identity for other cultural themes and safeguard for cultural diversity as local knowledge etc.
\end{abstract}

Keywords-Yugur folk song; dispersion; marginal storage; local knowledge

\section{INTRODUCTION}

Folk songs, as a cultural form of collective oral creation, oral circulation and oral processing in a certain region or a certain group, carry heavy local or group collective cultural memory. For the fact of Yugur having no words, no matter it is the "lack" originally or the "loss" later for various reasons, it will not prevent Yugur from remembering their cultural and historical as an instinct. Even though there are no written records, the subject will surely keep in mind of some things that can't be forgotten in other ways, just as Yugur people often say, "when I forget my hometown, I will never forget the language of my hometown; when I forget the language of my hometown, I will never forget the songs of my hometown." It can be seen that the significance of folk songs for Yugur cultural memory is special. Therefore, for Yugur nationality, which has language but no words, its folk songs carry more cultural functions and connotations.

\section{Yugur FOLK SONGS BeAR THE HISTORICAL TRACK OF ETHNIC GROUPS}

In order to resist the forgetting of the national roots caused by the absence of words, the ancestors of Yugur injected their cultural memory and collective experience into folk songs, which has been handed down from generation to generation. Historians, linguists and anthropologists have different emphases on interpreting the ethnic relationship of Yugur with their own unique research perspectives.

*Fund: the basic scientific research project of Northwest Minzu University for the Central universities "the construction of music discipline in ethnic universities and the protection of intangible cultural heritage of music in ethnic minority areas" (Project No.: 31920150156 ).
Although there is no complete consensus, they basically believe that in the whole historical context, Yugur has various connections with some other ancient ethnic groups such as Quigour, Dingling, salivius, Gaoche, Chellia, Xiongnu, and they all believe that the Yugur people living in Yugur Autonomous County located in South Gansu and Jiuquan Huangnibao are from other places. The most favorable evidence of this fact seems to come from Yugur folk songs, especially narrative songs such as "We Are from Hazhi in Xizhi" and "Songs on the Road".

The lyric meaning of "We Are from Hazhi in Xizhi":

There were conflicts and disputes among the tribe,

We set out from Hazhi in Xizhi.

We went east from Hazhi in Xizhi,

We trudged up a great distance,

$\cdots$

$\cdots$

The lyric of "Songs on the Road"

It's almost there. There is a place colored by yellow,

It's almost there, ...

Come here, come here, here is a stretch of land covered by yellow,

Come here, but what should father do? .....

Towards the Gobi Desert with mirage,

In the Gobi Desert, the remains of ancestors have an eternal sleep.

Yugur narrative folk songs not only record the reasons for the migration of ancestors, but also describe all kinds of painful experiences and scenes on the way. Perhaps it is the suffering of this experience that causes Yugur's descendants to consciously avoid this history for a long time. In addition, without the participation of words, this history is almost only left in folk songs. Maybe someone will ask why folk songs are not easy to be forgotten. That's what we're going to talk 
about - the tone of folk songs reinforces the memory of language.

\section{Yugur FolK SONG CONTINUES THE LIFE OF NATIVE LANGUAGE}

There is a generally accepted phenomenon that when singing, the fluent memory of the lyrics is more subconscious or even to the extent of muscle memory. However, when a singer is asked to recite the lyrics in the way of recitation after leaving behind the tune, the instant forgetting will appear. This phenomenon is especially obvious in oral epics. How can grand narrative epics be remembered by artists? In addition to the "formula" structure of epics, it is more important that epics are almost singing melody. Yugur narrative songs are mostly composed of the same melody but diverse lyrics, which may be regarded as fragments of oral epic. If the epic is presented in the form of "saying" or "speaking" without the element of "singing", will the artist still remember the huge length and will the oral epic still be handed down to this day?

Besides the influence of its natural ecology, the most direct origin to form the tune of folk song is the restriction of its native language tone. Yugur language in the West belongs to the Turkic language family of Altaic language branch and Altaic language branch belongs to agglutinating language, which is featured by that the word stress is generally on the last syllable. Accordingly, the rhythm stress of Yugur folk songs backward shifts. Yugur language in the East belongs to Mongolian language family of Altaic language branch and rhythm stress of its folk songs are basically similar to those of Yugur folk songs in the West. In other words, Yugur language is the internal driving force to support the tune characteristics of Yugur folk songs. Without Yugur native language, the core value of Yugur folk songs will be nearly broken up. Or it may lead to such a question: are the folk songs sung by Yugur people without Yugur language called Yugur folk songs?

\section{FolK SONGS CARRY YUGUR PEOPLE'S UNIQUE LIFE STYLE AND PRODUCTION EXPERIENCE}

Yugur folk songs bear Yugur people's production experience and lifestyle as a unique way to inherit Yugur people's labor experience, skills and customs. According to its functions, Yugur folk songs can be divided into narrative songs, wedding songs, pastoral songs, folk songs, hypnotic songs, toddler songs, funeral songs, yehezhe songs, stacker grass songs, songs of feeding young animals, rowing songs, praising songs and missing songs. Each theme song is based on Yugur people's unique production and life style.

The wedding song continues the process and norms of Yugur people's wedding ceremony. Yugur women have a ceremony of wearing their heads when they get married. In this process, the bride's uncle is required to sing a song of wearing head ornaments. In addition, there are singing links when leaving the mother's home and entertaining guests. It is worth noting that the role of uncle even exceeds that of father in the marriage custom of Yugur people. Researchers associate this phenomenon with Yugur matrilineal social and cultural form. If one day, the wedding ceremony of Yugur people will not follow the tradition, then the folk songs attached to the ceremony will no longer exist. Maybe the folk songs will still live alone without the ceremony, but the inherent cultural value it contains will gradually disappear.

Yugur's ancestors lived by herding. Correspondingly, a large number of pastoral songs and songs of feeding young animals were produced. Pastoral song is a kind of impromptu song, mainly including shepherd song, camel grazing song, etc. It is a dialogue between Yugur people and nature or themselves during grazing. The songs of feeding young animals are the words that Yugur people "say" to livestock. These songs reflect Yugur people's unique feelings for livestock, and only herdsmen who deal with livestock from generation to generation and regard livestock as "friends" will have such feelings and wisdom. When the mother does not feed the young animals, Yugur people will "pacify" or "persuade" her to feed the young with the songs. This way of touching and singing is indeed effective. What's more interesting is that these songs are different due to different livestock. Generally, they are divided into songs of feeding lamb (feeding sheep lamb, milk cotton lamb), songs of feeding horses, songs of feeding cow calf, songs of feeding camel lamb, etc. It should be noted that Yugur people don't think it's singing, but "saying" to animals. Later, with the change of Yugur people's lifestyle and concept, such "saying" gradually became "singing" and was moved to the stage. It is amazing that Yugur people's experience based on production and life coincides with the principle of music therapy. From this point of view, these Yugur folk songs have both aesthetic and practical functions of music. In addition to the songs of feeding young animals, labor songs such as "songs of making felt out of wool", "songs of piling grass", "songs of twisting thread" and "songs of weaving" have similar function with the above. They carry the labor experience of Yugur people and transmit the way of Yugur people's being.

If the songs of feeding young animals are Yugur people's "words" to animals, then Yehezhen song is Yugu people's language when they communicate with heaven or God. It is worth noting that the Yehezhen songs of Yugur people in the east of Mongolian are also sung in Yugur language in the West. Why is this so? In general, Yugur language in the East is more "official", especially in the Yuan Dynasty, which may indicate the historical situation of Mongolian culture and Yugur culture.

\section{Yugur FolK SONGS CONFIRM THE ORIGIN OF THE NATIONAL CULTURE OF THE SILK ROAD}

Yugur people settled down in the vital communications line of Hexi corridor after their migration. As a traffic fortress connecting the western regions and the Central Plains in history, this is the golden section of the Silk Road. Some anthropologists also call it the "national corridor" because it is the channel of national migration and the intersection of national culture. The national culture here influences the culture and life of Yugur people more or less. Therefore, Yugur folk songs are obviously influenced by the surrounding and communicating nations, and some 
evidences can be found from the words in the mother tongue system. For example, in Yugur language, "sartyer" represents "song of Hui nationality", purporting "flowers" or "juvenile"; "hediyer" represents "song of Han nationality", meaning "little tune" or "ditty"; and "datyar" means "song of Tibetan nationality", namely "wild tune". The author thinks that only when some foreign culture takes root and sprouts in the native culture, can the native language system give it the exclusive appellation. It can be seen that Yugur folk song is indeed deeply influenced by other folk song cultures.

From the vertical dimension of time, historians believe that the Yugur are closely related to the ancient ethnic groups of Dingling, Uighur, Gaoche and Xiongnu that no longer exist. Yugur people are far away from their cultural matrix after their long-distance migration. Although they are influenced by the surrounding national culture in the new settlement, their main cultural form still retains part of the original state. Perhaps the "dispersion" effect can be used to reveal the "marginal storage" of this culture. This "dispersion" leaves the context of the parent culture involuntarily. The separated people live in a foreign country, but they have a deep understanding of the culture of their home country, which is inextricably linked with their home country. However, they are caught in cognitive dissonance of "where is the home" and emotional entanglement in the host country. Perhaps because of this, people are forced to consciously or unconsciously feel the lack of words accompanied by recording "We Are from Hazhi in Xizhi" with songs and remembering the history and track of migration with "Songs on the Road", instinctively emphasizing "who I am", "where we come from", "what kind of people we are" and "how to live". This kind of "dispersion" culture continues the more ancient tradition. The preservation of this tradition spans time and space, constituting the "marginal preservation" of Yugur related ancient ethnic culture, and becoming the living sample of the study of ancient ethnic groups.

From the perspective of language, the Altaic language family goes along the Silk Road through Xinjiang to Kazakhstan Kyrgyzstan and other nearby countries. Due to the language features, the tones of folk songs based on intonation cannot be separated from Altaic language. From this point of view, Du Yaxiong's Comparative Study of Yugur Western folk Songs and Uygur Southern Xinjiang Muqam reveals the internal relations and similarities and differences between the southern Xinjiang Muqam and Western Yugur folk songs in terms of the characteristics of modes, development methods, rhythm forms, and rotation methods. On the other hand, the basis of historical coordinates of Yugur folk songs in the light of linguistic research can be explored. Linguists believe that the Yugur language in the West has preserved the linguistic features of ancient Uighurs and Turks, which means that the tunes of the Yugur folk songs in the West are likely to preserve the elements of ancient Uighurs' folk songs more. Differently, the eastern Yugur language is closer to the Mongolian language of the 3rd and 4th century, so the folk tune sung in the eastern Yugur language may be similar to the form of the ancient Mongolian folk song.
From the point of cross-border culture, folk songs once became an important evidence of the origin of Hungary and Yugur. It is said in the Biography of Uighur in the New Book of Tang that "Xiongnu is the ancestor of Uighur", there are also relevant records in ancient books such as the Biography of Gaoche in the Book of Wei and the Biography of Xirong in the Chronicles of the state of Wei, but there is a question about how to prove that Hungarians belong to the descendants of Xiongnu. At this time, music scholar Du Yaxiong finds the ancient Hungarian folk songs and Yugur folk songs are very similar both in tunes and lyrics. In 1982, he published a book named Comparative Study of Yugur Western folk Songs and Related Nationalities. Three years later, B. L. Gabor, a reporter of Hungarian Népszabadság, interviewed Du Yaxiong and heard the recording of Yugur folk songs collected by him. When listening to the songs, Gabor not only understood part of the lyrics, but also said that this was a recording of Yugur folk songs. Since then, more comparative performance and research based on the relationship between Yugur and Hungarian folk songs emerged, and the conclusions have been being more and more positive.

\section{Yugur FolK SONGS AS LOCAL KNOWLEDGE DEFEND CULTURAL DIVERSITY}

Globalization and modernization have become the trend of the times, which is clearing up relations between local and national cultural systems. Nowadays, culture has become more and more convergent, and the individuality and differences of local knowledge have been gradually eliminated. In fact, on the premise of cultural identity, it needs a variety of local knowledge, so there is a kind of multi-integrated civilization coexistence. Yugur folk song, as the contemporary existence of local knowledge, is helpful for defending the diversity of music culture.

On the other hand, the interpretation of Yugur folk songs, as a historical heritage, should pay attention to the temporal and spatial context of its historical dimension while examining its contemporary situation. The main body of folk songs is the specific people living in a specific time and space. As the crystallization of cultural practice, local knowledge contains Yugur people's collective historical memory and cultural foundation, which is the psychological root of their members' cultural identity. Therefore, the construction, inheritance and development of Yugur folk song culture not only proves its own subjectivity from the perspective of primitivism, but also promotes the identification and reconstruction of subjectivity in the contemporary context. Yugur folk song, as the local knowledge of historical narration, not only tells us the knowledge of the past, but also reflects its role and situation in the contemporary social and cultural identity system and structural relationship.

\section{CONCLUSION}

In the absence of words, Yugur folk songs become the unique symbol means of recording and inheriting the traditional culture, and it is the living storage of Yugur 
people's cultural memory. It not only strengthens the memory of oral language with the tone of folk songs, but also transmits the collective memory prototype, production experience and survival way of Yugur people in the past dynasties with the memory and spreading advantages of music. The form of Yugur folk songs hides the history and fact of music and culture exchange between Yugur people and surrounding ethnic groups, which proves the tradition and internal connection of cross-border ethnic culture exchange along the Silk Road. Yugur folk song, as a historical heritage, is a living fossil to study the ancient national language and music culture. Meanwhile, it is also the genetic symbol of Yugur people's cultural identity and the "cord blood" of Yugur folk song cultural reconstruction in the context of globalization.

\section{REFERENCES}

[1] Gansu Provincial Office of Integrated Editing of Folk Music. Integration of Chinese Folk Songs - Volume of Gansu Volume of Yugur, Dongxiang, Bao'an, Sala, Tu Nationality[Z]. 1986. (in Chinese)

[2] Zhang Shaoke. The Impact of Multicultural Identity of Dispersing Ethnic Groups on the Use of Social Media [J]. International Press, 2018 (3). (in Chinese)

[3] Du Yaxiong. A Comparative Study of Yugur Western Folk Songs and Uygur Southern Xinjiang Muqam [J]. Journal of Xinjiang Arts University, 2006 (4). (in Chinese)

[4] Gansu Provincial Cultural and Art Archives, Zhou Yongli. Volume 3 of Complete Works of Gansu Ethnic Folk Songs [Z]. Lanzhou: Gansu Culture Press, 2017. (in Chinese)

[5] Bu Jie. The Reason for the Similarity between Yugur Western Folk Songs and Hungarian Folk Songs: A Discussion with Zhang Rui [J]. Chinese Music 1985 (3). (in Chinese)

[6] Feng Guangyu, Yuan Bingchang. The History of Chinese Minority Music. Volume I [M]. Beijing: JINGWAH Press, 2007. (in Chinese)

[7] The Paradox of Intangible Cultural Live Inheritance: Preservation and Development [J]. Cultural Heritage, 2016 (5). (in Chinese) 